\title{
Analisa Pencarian Data *.Doc pada Komputer Menerapkan Metode Sequensial With Sentinel
}

\author{
Frengki Santoso \\ Program Studi Teknik Informatika, STMIK Budi Darma, Medan, Indonesia \\ Email: frengki707@gmail.com
}

\begin{abstract}
Abstrak-Dalam perkembangan komputer sering kali menemui masalah tentang bagaimana mendapatkan suatu data dalam kumpulan data yang banyak dan tipe data yang bermacam-macam. Dalam keperluannya untuk mencari data tersebut, terdapat beragam algoritma pencarian yaitu metode sequensial with Sentinel. Searching adalah pencarian data dengan menelusuri tempat pencarian data tersebut. Tempat pencarian data tersebut dapat berupa array dalam memori, bisa juga pada file pada external storage.Bila jumlah data sudah demikian besar, dibutuhkan suatu metode untuk mendapatkan data yang dibutuhkan. Beberapa metode pengorganisasian data telah membuat proses pencarian data menjadi lebih efisien. Dalam Permasalahan yang sering terjadi banyaknya data berektensi doc yang hilang tau lupa nama data yang disimpan maka dari itu diterapkan bagaimana mencari data yang berektensi doc yang ada dalam komputer.Suatu data yang terdapat pada media penyimpanan dengan metode pencarian ini dibuat dengan menggunakan algoritma pencarian yang menggunakan metode beruntun sehingga data yang dicari tau keberadaanya.dalam mengatasi masalah tersebut diterapakn Metode pencarian data berektensi doc agar dapat dilakukan dengan dua cara yaitu pencarian internal (internal searching) dan pencarian eksternal (external searching). Pada pencarian internal, semua rekaman yang diketahui berada dalam pengingat komputer sedangakan pada pencarian eksternal, tidak semua rekaman yang diketahui berada dalam pengingat komputer.
\end{abstract}

Kata Kunci: sequensial with Sentinel, algoritma pencarian, *.doc

Abstract-In the development of computers often encounter problems about how to get a data in a large data set and various types of data. In its need to find that data, there are various search algorithms, namely the sequential with Sentinel method. Searching is data search by searching where the data is searched. The place for searching the data can be an array in memory, it can also be in a file in external storage. When the amount of data is already so large, a method is needed to get the data needed. Several methods of organizing data have made the process of finding data more efficient. In the problem that often occurs a lot of lost doc data dimension or forget the name of the stored data and therefore applied how to find doc document data that is on the computer. A data contained in the storage media with this search method is created using a search algorithm that uses successive method so that the data sought knows its whereabouts. in overcoming the problem is applied The method of doc data extension can be done in two ways, namely internal search (internal searching) and external search (external searching). In an internal search, all records that are known to be in a computer reminder are on an external search, not all records that are known to be in a computer reminder.

Keywords: sequential with Sentinel, search algorithm, *. Doc

\section{PENDAHULUAN}

Pencarian data berektensi $d o c$ merupakan proses yang fundamental dalam pengolahan data. Proses pencarian data berektensi doc adalah menemukan nilai (data) tertentu di dalam sekumpulan data yang bertipe sama (baik bertipe dasar atau bertipe bentukan). Manusia sering menghabiskan waktu yang lama untuk memperoleh suatu informasi. Terlebih lagi informasi yang harus dicari dilakukan secara manual dan masih menggunakan kertas sebagai media pencarian informasi. Informasi merupakan perkembangan suatu fakta yang diolah menjadi data kemudian dikelola menjadi suatu informasi. Pada sekarang ini banyak metode yang sudah dipakai untuk memperoleh sebuah informasi yang diciptakan untuk membantu manusia. Informasi yang diperoleh baik berupa file teks maupun file yang berekstensi doc. Dalam perkembangan komputer sering kali menemui masalah tentang bagaimana mendapatkan suatu data dalam kumpulan data yang banyak dan tipe data yang bermacam-macam. Dalam keperluannya untuk mencari data tersebut, terdapat beragam algoritma pencarian (search algoritm). Searching adalah pencarian data dengan menelusuri tempat pencarian data tersebut. Tempat pencarian data tersebut dapat berupa array dalam memori, bisa juga pada file pada external storage.Bila jumlah data sudah demikian besar, dibutuhkan suatu metode untuk mendapatkan data yang dibutuhkan. Beberapa metode pengorganisasian data telah membuat proses pencarian data menjadi lebih efisien.

Dalam Permasalahan yang sering terjadi banyaknya data berektensi doc yang hilang tau lupa nama data yang disimpan maka dari itu diterapkan bagaimana mencari data yang berektensi doc yang ada dalam komputer.Suatu data yang terdapat pada media penyimpanan dengan metode pencarian ini dibuat dengan menggunakan algoritma pencarian yang menggunakan metode beruntun sehingga data yang dicari tau keberadaanya.dalam mengatasi masalah tersebut diterapakn Metode pencarian data berektensi $d o c$ agar dapat dilakukan dengan dua cara yaitu pencarian internal (internal searching) dan pencarian eksternal (external searching). Pada pencarian internal, semua rekaman yang diketahui berada dalam pengingat komputer sedangakan pada pencarian eksternal, tidak semua rekaman yang diketahui berada dalam pengingat komputer, tetapi ada sejumlah rekaman yang tersimpan dalam penyimpan luar misalnya pita atau cakram magnetis.

Dari jurnal terdahulu Implementasi Metode Sequential Dalam Pencarian Pendistribusian Barang Pada Cargo Integration Sistem yaitu Algoritma Sequential Search merupakan Algoritma pencarian linier, algoritma ini 
melakukan pencarian lebih cepat karena proses pencarian sudah dalam keadaan terurut [1] Dan dari jurnal terdahulu yang sama tentang metode sequensial with Sentinel Penerapan Algoritma Sequential Search dalam Proses Pencarian Informasi pada Sistem Pembelajaran Organ Jantung Manusia yaitu pencarian sequential with Sentinel dalam proses pencarian informasi pada sistem Pencarian berurutan bekerja dengan cara data yang ada dibandingkan satu per satu secara berurutan dengan yang dicari sampai data tersebut ditemukan atau data sudah diperiksa seluruhnya [2].

Algoritma pencarian yang menggunakan metode beruntun, yang dimana kita akan mengecek satu persatu data yang ingin dicari dari data pertama sampai terakhir, atau sebaliknya.Sehingga waktu yang dibutuhkan untuk pencarian data sangat cepat.Kemungkinan terburuk adalah jika data yang dicari terletak diindek sarray terakhir sehingga Waktu yang dibutuhkan untuk pencarian data sangat lama.Maka dilakukan penelitian pencarian data berekstensi doc pada komputer.

\section{METODE PENELITIAN}

\subsection{Doc}

Doc dan docx adalah dua format file atau ekstensi file yang digunakan di aplikasi Microsoft Word, salah satu aplikasi yang terdapat di paket aplikasi Microsoft Office. Format file doc digunakan di Microsoft Word 2003 dan versi sebelumnya, sedangkan docx digunakan di aplikasi Microsoft Word 2007 dan versi sesudahnya. Salah satu kendala yang ada di format file terbaru (docx) adalah terkait dengan kompatibilitas. Dokumen Microsoft Word yang disimpan menggunakan format file docx tidak dapat dibuka di Microsoft Word 2003 dan versi sebelumnya, sedangkan dokumen yang disimpan dalam format file doc dapat dibuka di Microsoft Word 2007 dan versi sesudahnya. Anda perlu menginstal Microsoft Office Compatibility Pack untuk membuka format file docx di versi Microsoft Word 2003 dan versi sebelumnya.[4]

\subsection{Pencarian}

Pencarian merupakan proses yang mendasar didalam pemrograman,pencarian (searching) merupakan tindakan untuk mendapatkan suatu data dalam sekumpulan data berdasarkan satu kunci (key) atau acuan data. Kegunaan beberapa struktur data dalam hubungannya untuk menyimpan data,sehingga memudahkan proses pencarian kembali tergantung pada:

1. Media penyimpanan data (memori, disk, tape).

2. Karakteristik jenis data yang disimpan.

3. Jumlah data yang akan disimpan dan keperluan untuk akses data secepat-cepatnya.

Terdapat bermacam persoalan pencarian dalam array yaitu :

1. Dari sekumpulan data akan dilakukan pencarian data $X$,maka hasil pencarian hanya menampikalkan suatu pesa "X" ditemukan atau X tidak ditemukan.

2. Dari sekumpulan data akan dilakukan pencarian data $\mathrm{X}$ andaikan data $\mathrm{X}$ ditemukan diposisi $\mathrm{n}$ dalam array,maka hasil pencarian akan menampilkan X ditemukan.

3. Dari sekumpulan data akan dilakukan pencarian data $X$,ternyata data $X$ terdapat lebih dari satu maka muncul pertanyaan data yang mana yang akan ditampilakan, apakah data yang pertama kali yang ditampilkan atau seluruh data yang ditemukan yang ditampilkan.dari ketiga persoalan diatas dapat dilakukan tergantung kebutuhan masing-masing.

Pencarian dapat dilakukan berdasarkan tempat penyimpanan yang dibagi atas dua yaitu pencarian internal dan pencarian eksternal.pencarian internal yaitu pencarian yang dilakukukan terhadap data yang berada dalam memori komputer.pencarian eksternal yaitu pencarian yang dilakukan terhadap data yang berada dalam memori eksternal. Pada umumnya dikenal tiga metode searching antara lain Sequential search,binary search dan interpolation search.[5]

\subsection{Metode sequensial}

Sequential search with sentinel ( pencarian beruntun) adalah proses membandingkan setiap elemen array satu persatu secara beruntun yang dimulai dari elemen pertama hingga elemen yang dicari ditemukan atau hingga elemen terakhir dari array. Sequential search dapat dilakukan terhadapa elemen array yang belum terurut atau terhadap elemen array yang terurut. Perbedaan dari keduanya terletak pada efisiensi operasi perbandingan yang dilakukan. Dengan kata lain sequential search akan mencari data dengan cara membandingkanya satu persatu dengan data yang ada.prosesnya tentu saja akan singkat jika data yang diolah sedikit,dan akan lama jika data yang sedikit saja.

\subsection{Sequensial Search Dengan Sentinel}

Teknik pencarian ini dilakukan dengan menambahkan elemen fiktif dalam suatu array dan ditempatkan pada posisi terakhir (nilai[N=1]) atau pada posisi pertama (nilai[1]) yang nilainya sama dengan elemen yang dicari.jika elemen fiktif diletakkan pada posisi terakhir maka pencarian dilakukan secara maju artinya pencarian dimulai dari posisi pertama hingga posisi terakhir.tetapi jika elemen fiktif diletakkan pada posisi pertama,maka pencarian dilakukan 
secara mundur artinya pencarian dimulai dari posisi terakhir hingga posisi pertama. Dengan demikian setiap kali dilakukan pencarian dengan metode ini pasti ditemukan hanya saja elemen yang ditemukan itu adalah elemen fiktif atau elemen yang sesungguhnya.misalkan elemen fiktif diletakkan pada posisi terakhir (nilai[N+1]) maka jika elemen yang ditemukan itu ada pada posisi pertama hingga posisi ke $\mathrm{N}$ berarti elemen yang dicari benar-benar ditemukan,artinya elemen tersebut memang benar ada dalam array.tetapi jika elemen yang ditemukan itu berada pada posisi $\mathrm{N}+1$ berarti elemen tidak ditemukan karena elemen yang ditemukan itu adalah elemen fiktif.

Bilangan yang akan dicari $=20$

Ukuran array menjadi $=(\mathrm{N}+1)$

Isi array Nilai[1..N+1] menjadi $=12,45,23,87,90,55,15,25,40,21,20$

Pemeriksaan dilakukan terhadap $=12,45,23,87,90,55,15,25,40,21,20$

Pada indeks $=1,2,3,4,5,6,7,8,9,10,11$

Karena 11 sama dengan $\mathrm{N}=1$ maka 20 tidak ditemukan [5]

\section{ANALISA DAN PEMBAHASAN}

Proses pencarian data berekstensi doc diawali dengan mengambil semua data yang berekstensi doc kemudian dilakukan pengelompokan data tersebut seperti halnya saat kita ingin mencari barang yang sama kemudian mencari spesifik dari barang atau file doc tersebut ini merupakan taha awal atau input dari proses analisa pencarian data berektensi doc.

Selanjutnya dilakukan pencarian dari fitur data doc dengan spesifikasi atau berdasarkan kata yang ingin dicari atau data yang ingin dicari.

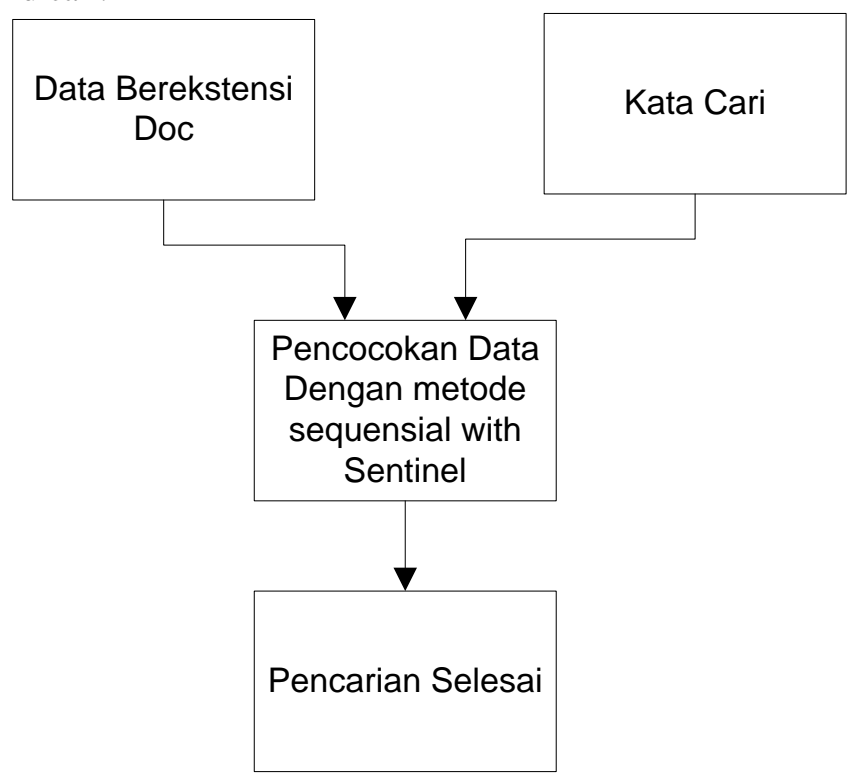

Gambar 1. Analisa Proses Pencarian Data Berekstensi Doc

Data berekstensi doc menjadi sebuah input pada pencarian ini menjadi bahan yang ingin diolah dan menjadi hasil dari penelitian ini, sedangkan kata yang ingin dicari merupakan data yang ingin disesuaikan dengan nama file doc sehinga tidak lagi membuka folder atau tempat berkasi pada komputer sehinga pencarian lebih cepat dengan menggunakan metode sequensial with sentimel.

File Doc merupakan data yang memliki nama file bebas oleh pengguna dan memiliki banyak data sehingga harus dikelompokan dulu pada sebuah sistem agar dapat diseleksi dengan baik sesuai prosedur dan aturan tertentu dalam pencarian teks berdasarkan nama file doc nantinya. Selanjtunya dibandingkan dengan kata cari yaitu biasanya seseorang ingin mencari kata doc dengan yang ingin ia temukan. Agar lebih jelas penulis membentuk sebuah gambar agar bisa dimengerti.

Tabel 1. File Doc

\begin{tabular}{|l|l|l|}
\hline \multirow{4}{*}{ Nama Folder } & \multicolumn{1}{|c|}{ Nama File } & Ekstensi \\
\hline \multirow{4}{*}{ Data Ku } & Frengki & Doc \\
\cline { 2 - 3 } & Laporan & Doc \\
\cline { 2 - 3 } & Bab I & Doc \\
\cline { 2 - 3 } & Catatan & Doc \\
\cline { 2 - 3 } & Surat lamaran & Doc \\
\cline { 2 - 3 } & Bab II & \\
\hline
\end{tabular}




\begin{tabular}{|l|l|l|}
\multirow{2}{*}{} & Data Kantor & Doc \\
\cline { 2 - 3 } & Tugas Skripsi & Doc \\
\cline { 2 - 3 } & Tugas Matakuliah & Doc \\
\hline
\end{tabular}

File Doc merupakan hal yang sangat penting dipahami untuk perses input yang akan dilakukan perbandingan kata-kata cari dalam tahap ini file doc dan kata cari akan dibahas semampu penulis untuk karya ilmiah ini.

\section{Penerapan Metode Sequensial With Sentinel}

Metode Sequensial With Sentinel (SWS ) adalah elemen fiktif yang sengaja ditambahkan sesudah elemen terakhir larik. Jika elemen larik terakhir L $[\mathrm{N}] \mathrm{L}$ merupakan panjang karakter membentuka kata atau kalimat dan $\mathrm{N}$ merupakan nilai dalam karakter, maka sentinel dipasang pada elemen L [N+1]. Sentinel ini menentukan apakah data yang di cari itu ada atau tidak ada. Sentinel ini diletakkan di akhir index larik. Berikut Tahapan Sentinel :

a. Tentukan Kalimat atau file doc

Kalimat pada sentinel merupakan kalimat yang penulis analisa yaitu berdasarkan folder dan nama file dari ekstensi doc. Dalam kasus ini penulis memilih, folder yang bernama "Dataku" dan nama file berekstensi doc dengan nama "Frengki" sehinga jika digabungkan menjadi "DatakulFrengki";

Misalkan data yang dicari $(\mathrm{X})=\mathrm{Ki}$ maka proses pencarian data adalah sebagai berikut:

1. Pencarian dimulai dari data elemen pada barisan bilangan 1

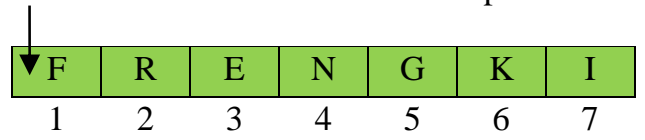

$\mathrm{N}=1: \mathrm{X}=\mathrm{Ki}$

While $(1<=7)$ And Not (False) $\quad$ True $\rightarrow$

If $(\mathrm{F}=\mathrm{R})$ Then Ealse

$\mathrm{I}=1+1=2$

2. Data tidak ditemukan, pencarian dilanjutkan ke data elemen kedua pada barisan bilangan 2 .

\begin{tabular}{|c|c|c|c|c|c|c|}
\hline $\mathrm{F}$ & $\pm R$ & $\mathrm{E}$ & $\mathrm{N}$ & $G$ & $\mathrm{~K}$ & I \\
\hline 1 & 2 & 3 & 4 & 5 & 6 & 7 \\
\hline
\end{tabular}

While $(2<=7)$ And Not (False) True $\rightarrow$

If $(\mathrm{R}=\mathrm{E})$ Then Edse

$\mathrm{I}=1+2=3$

3. Data tidak ditemukan, pencarian dilanjutkan ke data elemen ketiga pada barisan bilangan 3 .

\begin{tabular}{|c|c|c|c|c|c|c|}
\hline $\mathrm{F}$ & $\mathrm{R}$ & $\mathrm{V}$ & $\mathrm{N}$ & $\mathrm{G}$ & $\mathrm{K}$ & $\mathrm{I}$ \\
\hline 1 & 2 & 3 & 4 & 5 & 6 & 7
\end{tabular}

While $(3<=7)$ And Not (False) True $\rightarrow$

If $(\mathrm{E}=\mathrm{N})$ Then

$\mathrm{I}=3+1=4$

4. Data tidak ditemukan, pencarian dilanjutkan ke data elemen keempat pada barisan bilangan 4 .

\begin{tabular}{|c|c|c|c|c|c|c|}
\hline $\mathrm{F}$ & $\mathrm{R}$ & $\mathrm{E}$ & $\mathrm{N}$ & $\mathrm{G}$ & $\mathrm{K}$ & $\mathrm{I}$ \\
\hline 1 & 2 & 3 & \rfloor$^{4}$ & 5 & 6 & 7 \\
\hline
\end{tabular}

While $(4<=7)$ And Not (False) True $\rightarrow$

If $(\mathrm{N}=\mathrm{G})$ Then Fulse

$\mathrm{I}=4+1=5$

5. Data tidak ditemukan, pencarian dilanjutkan ke data elemen kelima pada barisan bilangan 5 .

\begin{tabular}{|c|c|c|c|c|c|c|}
\hline $\mathrm{F}$ & $\mathrm{R}$ & $\mathrm{E}$ & $\mathrm{N}$ & $\mathrm{G}$ & $\mathrm{K}$ & $\mathrm{I}$ \\
\hline 1 & 2 & 3 & 4 & 5 & 6 & 7 \\
\hline
\end{tabular}

While $(5<=7)$ And Not (False) True

If $(\mathrm{G}=\mathrm{K})$ Then Fatse

$\mathrm{I}=5+1=6$

6. Data ditemukan, pencarian dilanjutkan ke data elemen keenam pada barisan bilangan 6 . 


\begin{tabular}{|c|c|c|c|c|c|c|}
\multicolumn{1}{c}{ F } & R & E & N & G & $\mathbf{K}$ & I \\
\hline 1 & 2 & 3 & 4 & 5 & 6 & 7
\end{tabular}

While $(6<=7)$ And Not (False) True $\rightarrow$

If $(\mathrm{K}=\mathrm{I})$ Then

$\mathrm{I}=6+1=7$

Data ditemukan, pencarian dilanjutkan ke data elemen ketujuh pada barisan bilangan 7.

\begin{tabular}{|c|c|c|c|c|c|}
\hline $\mathrm{F}$ & $\mathrm{R}$ & $\mathrm{E}$ & $\mathrm{N}$ & $\mathrm{G}$ & $\mathrm{K} / \mathrm{I}$ \\
\hline 1 & 2 & 3 & 4 & 5 & 6 \\
\hline
\end{tabular}

While $(6<=7)$ And Not (False) $\rightarrow$ True

If $(\mathrm{A}=\mathrm{N})$ Then $\rightarrow$ True

$\mathrm{I}=7$

Data ditemukan, pencarian diberhentikan maka dari hasil pencarian data berektensi doc yaitu sebagai berikut

\begin{tabular}{|l|l|}
\hline $\mathrm{K}$ & $\mathrm{I}$ \\
\hline 6 & 7 \\
\hline
\end{tabular}

\section{KESIMPULAN}

Berdasarkan hasil dari pencarian data berektensi doc maka dapat maka dapat disimpulkan sebagai berikut:

1. Proses pencarian data berektensi Doc sesuai dengan data teks yang dicari maka dapat ditemukan dengan menggunakan metode sequensial with Sentinel.

2. Pencarian data berektensi Doc dilakukan dengan cara menentukan Data yang dicari lalu dilakukan dengan cara pencarian secara berurut jika data ketemu maka proses pencarian dihentikan.

\section{REFERENCES}

[1] Syafizal Helmi Situmorang, Analisis Data. medan, indonesia: usu press 2010, 2010.

[2] (2017) Gamepos. [Online]. https://gamepos.id/pengertian-analisa-menurut-10-para-ahli-dan-secara-umum diakses tgl $18 /$ juli/2018

[3] M. Agus J alam, belajar sendiri mengolah database dengan borland delphi 7. jakarta, indonesia: PT.elex media komputindo, 2003.

[4] https://www.termasmedia.com diakses tgl 02/agustus/2018

[5] Dayat Suryana, teknologi informasi dan komunikasi mengenal komputer. bandung, 2012.

[6] Haerul umam,soewarto hardienata,andi chairunnas, "IMPELEMENTASI ALGORITMA PENCARIAN SEQUENTIAL SEARCH PADA ENSIKLOPERIA IKAN HIAS AIR TAWAR BERBASIS ANDROID".

[7] wamiliana, "Penerapan Algoritma Sequential Search dalam Proses Pencarian Informasi pada Sistem Pembelajaran Organ Jantung Manusia ," jurnal komputasi, vol. 2 no 2, 2014.

[8] Abdullah Muhazir, "Implementasi Metode Sequential Dalam Pencarian Pendistribusian Barang Pada Cargo Integration Sistem ," sinkron, vol. 2 no 2, no. ISSN : 2541-2019, oktober 2017.

[9] Hendrayudi, Dasar-dasar Pemrograman Microsoft Visual Basic 2008. Bandung: Satu Nusa, 2010.

[10] Lamhot Sitorus, Algoritma dan pemograman, arie pramesta, Ed. yogyakarta, indonesia: andi, 2015. 